\title{
Pengaruh Konsentrasi dan Dosis Pupuk Organik Cair Terhadap Pertumbuhan Bibit Sengon Laut (Paraserianthes falcataria, L.)
}

\author{
Alfonsus Knaofmone \\ ${ }^{a}$ Fakultas Pertanian, Universitas Timor, Kefamenanu, TTU - NTT, 85613, Indonesia.
}

Article Info

Article history:

Received 14 September 2015

Received in revised form 20 September 2015 Accepted 18 Oktober 2015

Keywords:

Konsentrasi

Dosis

Pupuk Organik Cair

Sengon Laut

\section{Pendahuluan}

Paraserianthes falcataria, L. juga dikenal dengan nama sengon, merupakan salah satu jenis pionir serba guna yang sangat penting di Indonesia Jenis ini dipilih sebagai salah jenis tanaman hutan tanaman industri di Indonesia karena pertumbuhannya yang sangat cepat, mampu beradaptasi pada berbagai jenis tanah, karakteristik silvikulturnya yang bagus dan kualita kayunya dapat diterima untuk industri panel dan kayu pertukangan. Di beberapa lokasi di Indonesia, sengon berperan sangat penting baik dalam sistem pertanian tradisional maupun komersial.

Menurut Gunawan, (2011) sengon banyak digunakan dalam industri pertukangan, kayu lapis, kertas, maupun industri peti kemas. Jenis kayu in dinilai mampu mensubstitusi bahan baku kayu yang selama ini dibudidayakan dalam waktu relatif cepat. Sengon sudah dapat dipanen dengan diameter batang mencapai 30-40 $\mathrm{cm}$ dalam jangka waktu 5-6 tahun, tanaman sengon dapat tumbuh baik pada lahan-lahan dengan tingkat kesuburan rendah sehingga relatif memiliki kemampuan adaptasi yang tinggi.

Sengon mulai banyak dikembangkan sebagai hutan rakyat karena dapat tumbuh pada sebaran kondisi iklim yang luas, tidak menuntut persyaratan tempat tumbuh yang tinggi (Syahri, 1991 cit. Hadiyan, 2010). Menurut (Siregar et al., 2010), prospek penanaman sengon cukup baik, hal ini disebabkan karena kebutuhan akan kayu sengon mencapai $500.000 \mathrm{~m}^{3}$ pe tahun. Dengan adanya permintaan kayu yang tinggi ini maka permintaan bibi sengon juga semakin meningkat karena berkembang luasnya penanaman jenis ini untuk hutan tanaman industri dan hutan rakyat. Untuk mengembangkan pembudidayaan sengon perlu ketersediaan bibit yang berkualitas dalam jumlah yang mencukupi.

Wilayah Kabupaten Timor Tengah Utara didominasi oleh lahan kering yang tandus dengan lapisan top soil yang tipis sehingga dalam kegiatan budidaya pertanian dan kehutanan termasuk pembibitan sengon, sering kal tanaman mengalami kekurangan unsur hara, oleh karena itu dalam kegiatan tersebut perlu ditambahkan pupuk untuk menjamin ketersediaan unsur hara bag tanaman. Pemupukan mutlak dilakukan dalam membudidayakan tanaman dengan tujuan menggantikan unsur hara yang hilang karena proses pencucian dan pengangkutan bersama limbah pertanian.

Pupuk organik merupakan salah satu sumber hara bagi tanaman. Pupuk organik adalah pupuk yang sebagian besar atau seluruhnya terdiri atas bahan organik yang berasal dari tanaman atau hewan yang telah melalui proses rekayasa, dapat berbentuk padat atau cair. Untuk memudahkan unsur hara dapat diserap tanaman, bahan organik dapat dibuat menjadi pupuk cair terlebih dahulu, Pupuk organik cair lengkap mengandung unsur hara makro dan mikro serta bahan organik. Kelebihan dari pupuk organik cair diantaranya ialah kadar haranya tepat untuk kebutuhan tanaman, penggunaannya lebih efektif dan efesien, serta kemampuannya setara dengan pupuk organik murni (Lingga dan Marsono, 2001)

Novizan (2005) menyatakan agar pemupukan dapat berpengaruh secara efektif maka perlu memperhatikan beberapa hal, antara lain pemilihan jenis pupuk, pemakaian dosis/takaran yang sesuai dengan kebutuhan tanaman, dan cara penempatan pupuk. Menurut Lingga (2003), sebelum melakukan pemberian pupuk, konsentrasi yang dibuat harus benar-benar mengikuti petunjuk dalam kemasan. Osman (1996) juga menyatakan bahwa jika petan membuat konsentrasi yang lebih rendah dari yang dianjurkan, maka untuk mengimbanginya penyemprotan pupuk bisa dipercepat atau diperpendek interval waktunya pemberiannya.

Efektivitas dan efisiensi penggunaan pupuk organik cair di lapangan ditentukan oleh berbagai faktor diantaranya yaitu ketepatan pemilihan jenis, konsentrasi, dosis, cara dan waktu aplikasi pupuk. Menurut hasil penelitian Indah (2006) yang membandingkan pemberian pupuk organik cair dengan konsentrasi 1, 2 dan $3 \mathrm{ml} / \mathrm{l}$ air pada tanaman cabe berpengaruh secara nyata terhadap beberapa parameter pertumbuhan dan hasil tanaman dengan perlakuan $3 \mathrm{ml} / \mathrm{l}$ air sebagai konsentrasi yang paling optimum. Hasil penelitian Rambitan dan (Rambitan dan Sari, 2015) yang membandingkan pemberian pupuk kompos cair dengan dosis kontrol, $150 \mathrm{ml}, 200 \mathrm{ml}$ dan $250 \mathrm{ml}$ pada tanaman kacang tanah berpengaruh secara nyata terhadap beberapa parameter pertumbuhan dan hasil tanaman dengan perlakuan $250 \mathrm{ml}$ sebagai dosis yang paling optimum.

Permasalahannya adalah belum diketahui tentang pengaruh konsentrasi dan dosis pupuk organik cair terhadap pertumbuhan bibit sengon laut sehingga dianggap perlu melakukan penelitian tentang "Pengaruh Konsentrasi dan Dosi Pupuk Organik Cair Terhadap Pertumbuhan Bibit Sengon Laut". Penelitian ini bertujuan untuk mengetahui pengaruh konsentrasi dan dosis pupuk organik cair terhadap pertumbuhan bibit sengon laut serta mengetahui konsentrasi dan dosis pupuk organik cair yang tepat untuk pertumbuhan bibit sengon laut yang optimum

\section{Metode}

2.1 Waktu dan Tempat

Penelitian ini dilaksanakan pada bulan Juni sampai November 2015 di kebun percobaan Fakultas Pertanian, Universitas Timor Kelurahan Sasi, Kecamatan Kota Kefamenanu, Kabupaten TTU. Topografi berbukit-buki dengan ketinggian $\pm 400 \mathrm{~m} \mathrm{dpl}$, curah hujan 900-1.500 mm per tahun, suhu udara berkisar antara $27^{\circ} \mathrm{C}$ (BPS Kab. TTU, 2007).

\subsection{Rancangan Percobaan}

Penelitian mengunakan Rancangan Acak Kelompok (RAK) faktorial 3 x 3 yang diulang tiga kali. Faktor pertama adalah konsentrasi pupuk organik cair (K) yang terdiri dari tiga aras yaitu $1 \mathrm{ml} / \mathrm{l}$ air $\left(\mathrm{k}_{1}\right), 3 \mathrm{ml} / \mathrm{l}$ air $\left(\mathrm{k}_{2}\right)$ dan $5 \mathrm{ml} / \mathrm{l}$ air $\left(\mathrm{k}_{3}\right)$. Faktor kedua adalah dosis pupuk organik cair (D) yang terdiri dari tiga aras yaitu $200 \mathrm{ml} /$ polybag $\left(\mathrm{d}_{1}\right), 250 \mathrm{ml} /$ polybag $\left(\mathrm{d}_{2}\right)$ dan $300 \mathrm{ml} /$ polybag $\left(\mathrm{d}_{3}\right)$ Kombinasi perlakuannya antara lain $\mathrm{k}_{1} \mathrm{~d}_{1}, \mathrm{k}_{1} \mathrm{~d}_{2}, \mathrm{k}_{1} \mathrm{~d}_{3}, \mathrm{k}_{2} \mathrm{~d}_{1}, \mathrm{k}_{2} \mathrm{~d}_{2}, \mathrm{k}_{2} \mathrm{~d}_{3}, \mathrm{k}_{3} \mathrm{~d}_{1}, \mathrm{k}_{3} \mathrm{~d}_{2}$ dan $\mathrm{k}_{3} \mathrm{~d}_{3}$.

\subsection{Pelaksanaan Penelitian}

a. Persiapan Benih

Benih yang digunakan dalam penelitian ini adalah benih Sengon Laut yang diambil dari C.V. Timor Raya yang beralamat di Km. 9 jurusan Kupang. Benih berasal dari pohon induk tanaman Sengon yang memiliki sifat-sifat genetik yang baik, bentuk fisiknya tegak lurus dan tegar, tidak menjadi inang dari hama dan penyakit. Benih yang dibutuhkan dalam penelitian ini sebanyak $675 \mathrm{biji}$ dengan benih cadangan sebanyak $10 \%$ sehingga jumlah benih yang disiapkan sebanyak 742 biji. Benih diseleksi dengan cara memilih biji yang memiliki kulit bersih, berwarna coklat tua, ukuran benih maksimum, tenggelam dalam air ketika benih direndam dan bentuk benih masih utuh

b. Persiapan Lahan Pembibitan

Lahan dibersihkan dari gulma dan serta vegetasi lainnya. Lahan yang digunakan berukuran panjang 9,5 $\mathrm{m}$ dan lebar 2,5 $\mathrm{m}$ dengan luas $23, \mathrm{~m}^{2}$. Lahan dibagi dalam tiga blok dan pada masing-masing blok dibuat sembilan petak percobaan dengan ukuran panjang $50 \mathrm{~cm}$ dan lebar $50 \mathrm{~cm}$ sehingga secar keseluruhan terdapat 27 petak. Pembuatan petak percobaan menggunakan patok kayu dan tali rafia. Jarak antara petak $0,5 \mathrm{~m}$ dan jarak antara blok $1 \mathrm{~m}$. Pada setiap blok, petak dan tanaman sampel diberikan label menggunakan tiang bambu dan seng. Lahan percobaan kemudian diberikan naungan setinggi $2 \mathrm{~m}$ dengan bahan kayu dan alang-alang.

c. Persiapan Media Tanam

Media tanam yang digunakan adalah tanah hasil ayakan dicampur dengan bokashi dengan perbandingan $2: 1$. Media kemudian dimasukan dalam polybag berukuran diameter $10 \mathrm{~cm}$ dan tinggi $20 \mathrm{~cm}$. Terdapat 675 polybag yang kemudian disusun dalam petak-petak percobaan. Setiap petak percobaan terdapat 25 polybag

d. Penyemaian Benih

Benih disemaikan dalam bak kecambah plastik dengan media kecambah berupa campuran tanah, pasir dan pupuk kandang sapi. Sebelum disemaikan benih direndam dalam air panas dengan suhu $80{ }^{\circ} \mathrm{C}$ selama 30 menit, setelah itu benih direndam kembali dalam air dingin selama 24 jam. Benih kemudian 
ditabur dalam larikan yang sudah dibuat sebelumnya pada media kecambah. Jarak antara larikan $5 \mathrm{~cm}$ dengan kedalaman $2 \mathrm{~cm}$. Benih yang ditabur tidak saling tumpang tindih agar pertumbuhan kecambah tidak bertumpuk, selanjutnya benih ditutup dengan media kecambah. Penyiraman dilakukan pada pagi dan sore hari dengan menggunakan hand sprayer.

e. Penyapihan

Penyapihan dilakukan setelah kecambah berumur 15 hari dengan cara mengangkat kecambah yang sehat dari media kecambah kemudian ditanam dalam polybag pada sore hari, setiap polybag ditanam satu tanaman sehingga dalam setiap petak percobaan terdapat 25 populasi tanaman dengan jumlah populasi keseluruhan 675 tanaman.

f. Pembuatan dan Aplikasi Pupuk Organik Cair

Bahan yang digunakan untuk pembuatan pupuk cair adalah cirit sapi yang masih mentah, daun gamal, daun lamtoro, daun gala-gala, EM-4 dan air. Semua bahan organik dicampur kemudian disiram sampai lembab, campurkan EM-4 dengan ukuran satu tutupan botol EM-4 untuk satu liter air percik pada semua bahan. Bahan dimasukan dalam karung kemudian diikat dengan menggunakan tali rafia, selanjutnya dimasukan ke dalam air yang sudah disediakan dan ditutup rapat dan disimpan selama 1 minggu. Aplikasi pupuk cair dilakukan dengan cara penyiraman menggunakan gelas ukur. Pemberian dilakukan setiap tujuh hari sekali selama penelitian mulai bibit berumur 14 Hari Setelah Sapih (HSS). Dosis rata-rata setiap kali pemberian sesuai perlakuan yakni 200 $\mathrm{ml} /$ polybag, $250 \mathrm{ml} /$ polybag dan $300 \mathrm{ml} /$ polybag yang diberikan semakin banyak mengikuti pertambahan umur tanaman. Konsentrasi pupuk organik cair disesuaikan dengan perlakuan yaitu pada sembilan petak diberikan pupuk organik cair dengan konsentrasi $1 \mathrm{ml} / \mathrm{l}$ air, pada sembilan petak diberikan pupuk organik cair dengan konsentrasi $3 \mathrm{ml} / \mathrm{l}$ air dan pada sembilan petak diberikan pupuk organik cair dengan konsentrasi $5 \mathrm{~m} / \mathrm{l}$ air.

g. Penyiraman

Penyiraman dilakukan dua kali sehari yakni pada pagi dan sore hari menggunakan hand sprayer hingga tanaman berumur 20 HSS, selanjutnya penyiraman menggunakan gembor

h. Penyulaman

Penyulaman dilakukan pada saat tanaman berumur 15 HSS. Penyulaman dilakukan dengan cara mengganti bibit yang mati atau rusak dengan bibit cadangan yang telah disiapkan.

i. Penyiangan

Penyiangan terhadap gulma dilakukan dengan mencabutnya dan bila perlu dibantu dengan alat pencungkil, namun dilakukan hati-hati agar jangan sampai akar bibit Sengon terganggu.

\subsection{Parameter Pengamatan}

a. Tinggi Tanaman $(\mathrm{cm})$

Tinggi tanaman diukur dengan menggunakan penggaris pada lima tanaman sampel. Anakan diukur mulai dari leher akar yaitu batas antara batang dengan akar di atas permukaan tanah hingga pucuknya. Pengukurannya dilakukan pada saat bibit berumur 30 HSS, 60 HSS dan 90 HSS.

b. Diameter Batang ( $\mathrm{mm})$

Pengukuran diameter batang dilakukan dengan menggunakan jangka sorong dengan cara menjepit pada bagian batang $(1 \mathrm{~cm}$ di atas pangkal batang) dari lima tanaman sampel. Pengukuran dilakukan pada saat bibit berumur 30 HSS, 60 HSS dan 90 HSS.

c. Panjang Akar Primer $(\mathrm{cm})$

Panjang akar diukur dengan menggunakan penggaris pada lima tanaman sampel. Akar diukur mulai dari leher akar yaitu batas antara batang dengan akar hingga ujung akar. Pengukurannya dilakukan pada saat bibit berumur 90 HSS

d. Berat Segar Bibit (g)

Pengukuran berat segar bibit dilakukan pada semua organ lima tanaman sampel yang dilakukan pada saat bibit berumur 90 HSS. Pengukuran dilakukan dengan cara memisahkan tanaman dari media tanam, kemudian akar dibersihkan dari kotoran atau tanah yang menempel. Selanjutnya semua organ dibersihkan kemudian ditimbang berat segarnya. Penimbangan menggunakan timbangan analitik.

\section{e. Berat Kering Bibit (g)}

Pengukuran berat kering bibit dilakukan pada semua organ lima tanaman sampel yang dilakukan pada saat bibit berumur 90 HSS. Pengukuran dilakukan dengan cara menimbang semua organ tanaman setelah dikeringkan dalam oven dengan suhu $105{ }^{\circ} \mathrm{C}$ selama 24 jam. Penimbangan menggunakan timbangan analitik.

\subsection{Analisis Data}

Data hasil pengamatan kemudian dianalisis dengan menggunakan sidik ragam (Anova) Rancangan Acak Kelompok (RAK). Rata-rata perlakuan selanjutnya diuji lanjut dengan menggunakan Duncan Multiple Range Test (DMRT) dengan tingkat signifikasi 5\% sesuai petunjuk Gomez and Gomez (1984). Analisis data menggunakan program SAS 9.1.

\section{Hasil dan Pembahasan}

\subsection{Tinggi Tanaman}

Pertambahan tinggi tanaman terus mengalami peningkatan pada setiap waktu pengamatan, besarnya laju pertambahan tinggi berbeda-beda untuk setiap perlakuan. Hasil sidik ragam (Anova) menunjukkan tidak terjadi interaksi antara konsentrasi dan dosis pupuk organik cair terhadap tinggi tanaman setiap waktu pengamatan

Konsentrasi pupuk organik cair berpengaruh nyata terhadap tinggi tanaman waktu pengamatan 30 HSS dimana tanaman yang diberikan pupuk organik cair dengan konsentrasi $3 \mathrm{ml} / \mathrm{l}$ air paling tinggi dan berbeda nyata dengan tinggi tanaman yang diberikan pupuk organik cair dengan konsentrasi $1 \mathrm{ml} / \mathrm{l}$ air maupun $5 \mathrm{ml} / \mathrm{l}$ air yang sama tinggi. Pada pengamatan $60 \mathrm{HSS}$ dan $90 \mathrm{HSS}$, konsentrasi pupuk organik cair tidak berpengaruh nyata terhadap tinggi tanaman tetapi data Tabel 1. menunjukkan bahwa tanaman yang diberikan pupuk organik cair dengan konsentrasi $3 \mathrm{ml} / \mathrm{l}$ air selalu cenderung lebih tinggi sedangkan tanaman yang diberikan pupuk organik cair dengan konsentrasi 5 $\mathrm{ml} / \mathrm{l}$ air selalu paling pendek.

\section{Tabel 1. Tinggi Tanaman $(\mathrm{cm})$}

\begin{tabular}{|c|c|c|c|c|c|}
\hline \multirow{2}{*}{$\begin{array}{c}\text { Waktu } \\
\text { Pengamatan }\end{array}$} & \multirow{2}{*}{$\begin{array}{l}\text { Konsentrasi } \\
\text { (ml/1 air) }\end{array}$} & \multicolumn{3}{|c|}{ Dosis (ml/polybag) } & \multirow{2}{*}{ Rerata } \\
\hline & & 200 & 250 & 300 & \\
\hline \multirow{4}{*}{$30 \mathrm{HSS}$} & 1 & 4,9 abc & $4,3 \mathrm{c}$ & $4,4 \mathrm{bc}$ & $4,5 \mathrm{~b}$ \\
\hline & 3 & $4,8 \mathrm{abc}$ & $5,3 \mathrm{ab}$ & $5,6 \mathrm{a}$ & $5,2 \mathrm{a}$ \\
\hline & 5 & $4,5 \mathrm{bc}$ & $4,5 \mathrm{bc}$ & $4,6 \mathrm{bc}$ & $4,5 \mathrm{~b}$ \\
\hline & Rerata & $4,7 \mathrm{a}$ & $4,7 \mathrm{a}$ & $4,9 \mathrm{a}$ & $(-)$ \\
\hline \multirow{4}{*}{$60 \mathrm{HSS}$} & 1 & $7,0 \mathrm{a}$ & $6,7 \mathrm{a}$ & $7,4 \mathrm{a}$ & $7,0 \mathrm{a}$ \\
\hline & 3 & $6,8 \mathrm{a}$ & $7,5 \mathrm{a}$ & $8,2 \mathrm{a}$ & $7,5 \mathrm{a}$ \\
\hline & 5 & $6,7 \mathrm{a}$ & $6,3 \mathrm{a}$ & $6,7 \mathrm{a}$ & $6,6 \mathrm{a}$ \\
\hline & Rerata & $6,9 \mathrm{a}$ & $6,8 \mathrm{a}$ & $7,4 \mathrm{a}$ & $(-)$ \\
\hline \multirow{4}{*}{$90 \mathrm{HSS}$} & 1 & $15,6 \mathrm{a}$ & $15,6 \mathrm{a}$ & $17,1 \mathrm{a}$ & $16,1 \mathrm{a}$ \\
\hline & 3 & $13,2 \mathrm{a}$ & $16,2 \mathrm{a}$ & $17,9 \mathrm{a}$ & $15,8 \mathrm{a}$ \\
\hline & 5 & $16,9 \mathrm{a}$ & $14,2 \mathrm{a}$ & $15,5 \mathrm{a}$ & $15,5 \mathrm{a}$ \\
\hline & Rerata & $15,2 \mathrm{a}$ & $15,3 \mathrm{a}$ & $16,8 \mathrm{a}$ & $(-)$ \\
\hline Keterangan & $\begin{array}{l}\text { Angka pada ba } \\
\text { tidak berbeda } 1 \\
(-) \text { : Tidak ter }\end{array}$ & $\begin{array}{l}\text { lan kolor } \\
\text { menuru } \\
\text { interaksi }\end{array}$ & $\begin{array}{l}\text { diikuti } \\
\text { MRT } \alpha 5 \\
\text { faktor }\end{array}$ & gan huruf & g sama \\
\hline
\end{tabular}

Dosis pupuk organik cair juga tidak berpengaruh nyata terhadap tinggi tanaman setiap waktu pengamatan tetapi tanaman yang diberikan pupuk organik cair dengan dosis $300 \mathrm{ml} /$ polybag selalu cenderung lebih tinggi. Pada 30 HSS dan 90 HSS tanaman yang diberikan pupuk organik cair dengan dosis $200 \mathrm{ml} /$ polybag selalu paling pendek sedangkan pada pengamatan $60 \mathrm{HSS}$ tanaman yang diberikan pupuk organik cair dengan dosis $250 \mathrm{ml} /$ polybag selalu paling pendek.

\subsection{Diameter Batang}

Batang tanaman terus bertambah besar selama penelitian. Hasil sidik ragam (Anova) menunjukkan bahwa tidak terjadi interaksi antara konsentrasi dan dosis pupuk organik cair terhadap diameter batang setiap waktu pengamatan.

Konsentrasi pupuk organik cair tidak berpengaruh nyata terhadap diameter batang setiap waktu pengamatan tetapi data Tabel 2. menunjukkan bahwa batang tanaman yang diberikan pupuk organik cair dengan konsentrasi $3 \mathrm{ml} / \mathrm{l}$ air selalu cenderung lebih besar sedangkan batang tanaman yang diberikan pupuk organik cair dengan konsentrasi $1 \mathrm{ml} / 1$ air paling kecil pada pengamatan 30 HSS, sedangkan pada 60 HSS dan 90 HSS batang tanaman yang diberikan pupuk organik cair dengan konsentrasi $5 \mathrm{ml} / \mathrm{l}$ air paling kecil.

Dosis pupuk organik cair juga tidak berpengaruh nyata terhadap diameter batang setiap waktu pengamatan tetapi batang tanaman yang diberikan pupuk organik cair dengan dosis $300 \mathrm{ml} /$ polybag selalu cenderung lebih besar. Pada 30 HSS, batang tanaman yang diberikan pupuk organik cair dengan dosis 250 $\mathrm{ml} /$ polybag paling kecil sedangkan pada pengamatan $60 \mathrm{HSS}$ dan $90 \mathrm{HSS}$ batang tanaman yang diberikan pupuk organik cair dengan dosis 200 $\mathrm{ml} /$ polybag selalu paling kecil.

\section{Tabel 2. Diameter Batang (mm)}

\begin{tabular}{|c|c|c|c|c|c|}
\hline \multirow{2}{*}{$\begin{array}{c}\text { Waktu } \\
\text { Pengamatan }\end{array}$} & \multirow{2}{*}{$\begin{array}{c}\text { Konsentrasi } \\
\text { (ml/1 air) }\end{array}$} & \multicolumn{3}{|c|}{ Dosis (ml/polybag) } & \multirow{2}{*}{ Rerata } \\
\hline & & 200 & 250 & 300 & \\
\hline \multirow{4}{*}{$30 \mathrm{HSS}$} & 1 & $0,76 \mathrm{a}$ & $0,70 \mathrm{a}$ & $0,75 \mathrm{a}$ & $0,73 \mathrm{a}$ \\
\hline & 3 & $0,78 \mathrm{a}$ & $0,81 \mathrm{a}$ & $0,82 \mathrm{a}$ & $0,80 \mathrm{a}$ \\
\hline & 5 & $0,74 \mathrm{a}$ & $0,72 \mathrm{a}$ & $0,76 \mathrm{a}$ & $0,74 \mathrm{a}$ \\
\hline & Rerata & $0,76 \mathrm{a}$ & $0,74 \mathrm{a}$ & $0,77 \mathrm{a}$ & $(-)$ \\
\hline \multirow{4}{*}{$60 \mathrm{HSS}$} & 1 & $1,50 \mathrm{a}$ & $1,56 \mathrm{a}$ & $1,66 \mathrm{a}$ & $1,58 \mathrm{a}$ \\
\hline & 3 & $1,58 \mathrm{a}$ & $1,66 \mathrm{a}$ & $1,67 \mathrm{a}$ & $1,64 \mathrm{a}$ \\
\hline & 5 & $1,46 \mathrm{a}$ & $1,41 \mathrm{a}$ & $1,57 \mathrm{a}$ & $1,48 \mathrm{a}$ \\
\hline & Rerata & $1,51 \mathrm{a}$ & $1,55 \mathrm{a}$ & $1,64 \mathrm{a}$ & $(-)$ \\
\hline \multirow{4}{*}{$90 \mathrm{HSS}$} & 1 & $2,67 \mathrm{a}$ & $2,79 \mathrm{a}$ & $2,81 \mathrm{a}$ & $2,76 \mathrm{a}$ \\
\hline & 3 & $2,60 \mathrm{a}$ & $2,81 \mathrm{a}$ & $2,94 \mathrm{a}$ & $2,78 \mathrm{a}$ \\
\hline & 5 & $2,78 \mathrm{a}$ & $2,49 \mathrm{a}$ & $2,60 \mathrm{a}$ & $2,62 \mathrm{a}$ \\
\hline & Rerata & $2,68 \mathrm{a}$ & $2,70 \mathrm{a}$ & $2,78 \mathrm{a}$ & $(-)$ \\
\hline Keterangan : & $\begin{array}{l}\text { Angka pada ba } \\
\text { tidak berbeda } n \\
(-) \text { : Tidak ter }\end{array}$ & $\begin{array}{l}\text { n kolon } \\
\text { nenurut } \\
\text { nteraksi }\end{array}$ & $\begin{array}{l}\text { ng diiku } \\
\text { PMRT o } \\
\text { r faktor }\end{array}$ & gan huru & g sama \\
\hline
\end{tabular}

3.3 Panjang Akar

Hasil sidik ragam (Anova) menunjukkan bahwa tidak terjadi interaksi antara konsentrasi dan dosis pupuk organik cair terhadap panjang akar. Konsentrasi pupuk organik cair tidak berpengaruh nyata terhadap panjang akar 
tetapi data Tabel 3. menunjukkan bahwa akar tanaman yang diberikan pupuk organik cair dengan konsentrasi $1 \mathrm{ml} / \mathrm{l}$ air cenderung lebih panjang sedangkan akar tanaman yang diberikan pupuk organik cair dengan konsentrasi 5 ml/l air paling pendek. Dosis pupuk organik cair juga tidak berpengaruh nyata terhadap panjang akar tetapi akar tanaman yang diberikan pupuk organik cair dengan dosis $300 \mathrm{ml} /$ polybag cenderung lebih panjang sedangkan akar tanaman yang diberikan pupuk organik cair dengan dosis $200 \mathrm{ml} /$ polybag paling pendek.

Tabel 3. Panjang Akar $(\mathrm{cm})$

\begin{tabular}{ccccc}
\hline Konsentrasi & \multicolumn{3}{c}{ Dosis (ml/polybag) } & \multirow{2}{*}{ Rerata } \\
\cline { 2 - 4 }$(\mathrm{ml} / \mathrm{l}$ air) & 200 & 250 & 300 & \\
\hline 1 & $38,7 \mathrm{a}$ & $36,0 \mathrm{a}$ & $41,4 \mathrm{a}$ & $38,7 \mathrm{a}$ \\
3 & $35,3 \mathrm{a}$ & $35,8 \mathrm{a}$ & $40,4 \mathrm{a}$ & $37,1 \mathrm{a}$ \\
5 & $34,7 \mathrm{a}$ & $38,5 \mathrm{a}$ & $36,7 \mathrm{a}$ & $36,6 \mathrm{a}$ \\
\hline Rerata & $36,2 \mathrm{a}$ & $36,8 \mathrm{a}$ & $39,5 \mathrm{a}$ & $(-)$ \\
\hline Keterangan : & Angka pada baris dan kolom yang diikuti dengan huruf & yang sama \\
& tidak berbeda nyata menurut uji DMRT $\alpha$ 5\% & \\
& $(-)$ : Tidak terjadi interaksi antar faktor &
\end{tabular}

\subsection{Berat Segar Bibit}

Hasil sidik ragam (Anova) menunjukkan bahwa tidak terjadi interaksi antara konsentrasi dan dosis pupuk organik cair terhadap berat segar bibit. Konsentrasi pupuk organik cair tidak berpengaruh nyata terhadap berat segar bibit tetapi data Tabel 4. menunjukkan bahwa berat segar bibit yang diberikan pupuk organik cair dengan konsentrasi $1 \mathrm{ml} / \mathrm{l}$ air cenderung lebih berat sedangkan berat segar bibit yang diberikan pupuk organik cair dengan konsentrasi $3 \mathrm{ml} / \mathrm{l}$ air paling ringan. Dosis pupuk organik cair juga tidak berpengaruh nyata terhadap berat segar bibit tetapi bibit yang diberikan pupuk organik cair dengan dosis $200 \mathrm{ml} /$ polybag cenderung lebih berat sedangkan bibit yang diberikan pupuk organik cair dengan dosis $300 \mathrm{ml} /$ polybag paling ringan.

Tabel 4. Berat Segar Bibit (g)

\begin{tabular}{ccccc}
\hline Konsentrasi & \multicolumn{3}{c}{ Dosis (ml/polybag) } & \multirow{2}{*}{ Rerata } \\
\cline { 2 - 4 }$(\mathrm{ml} / 1$ air $)$ & 200 & 250 & 300 & \\
\hline 1 & $7,7 \mathrm{a}$ & $7,4 \mathrm{a}$ & $7,4 \mathrm{a}$ & $7,5 \mathrm{a}$ \\
3 & $6,1 \mathrm{a}$ & $6,5 \mathrm{a}$ & $5,6 \mathrm{a}$ & $6,1 \mathrm{a}$ \\
5 & $8,5 \mathrm{a}$ & $6,7 \mathrm{a}$ & $6,9 \mathrm{a}$ & $7,4 \mathrm{a}$ \\
\hline Rerata & $7,4 \mathrm{a}$ & $6,9 \mathrm{a}$ & $6,7 \mathrm{a}$ & $(-)$ \\
\hline Keterangan : & Angka pada baris dan kolom yang diikuti dengan huruf yang sama & \\
& tidak berbeda nyata menurut uji DMRT $\alpha$ 5\% & \\
& $(-)$ : Tidak terjadi interaksi antar faktor &
\end{tabular}

\subsection{Berat Kering Bibit}

Hasil sidik ragam (Anova) menunjukkan bahwa tidak terjadi interaksi antara konsentrasi dan dosis pupuk organik cair terhadap berat kering bibit. Konsentrasi pupuk organik cair tidak berpengaruh nyata terhadap berat kering bibit tetapi data Tabel 5. menunjukkan bahwa berat kering bibit yang diberikan pupuk organik cair dengan konsentrasi $3 \mathrm{ml} / \mathrm{l}$ air cenderung lebih berat sedangkan berat kering bibit yang diberikan pupuk organik cair dengan konsentrasi $5 \mathrm{ml} / \mathrm{l}$ air paling ringan. Dosis pupuk organik cair juga tidak berpengaruh nyata terhadap berat kering bibit tetapi bibit yang diberikan pupuk organik cair dengan dosis $300 \mathrm{ml} /$ polybag cenderung lebih berat sedangkan bibit yang diberikan pupuk organik cair dengan dosis $250 \mathrm{ml} /$ polybag paling ringan.

$\underline{\text { Tabel 5. Berat Kering Bibit (g) }}$

\begin{tabular}{ccccc}
\hline Konsentrasi & \multicolumn{3}{c}{ Dosis (ml/polybag) } & \multirow{2}{*}{ Rerata } \\
\cline { 2 - 4 }$(\mathrm{ml} / 1$ air $)$ & 200 & 250 & 300 & \\
\hline 1 & $2,0 \mathrm{a}$ & $1,8 \mathrm{a}$ & $2,1 \mathrm{a}$ & $2,0 \mathrm{a}$ \\
3 & $1,7 \mathrm{a}$ & $2,0 \mathrm{a}$ & $2,5 \mathrm{a}$ & $2,1 \mathrm{a}$ \\
5 & $2,2 \mathrm{a}$ & $1,7 \mathrm{a}$ & $1,9 \mathrm{a}$ & $1,9 \mathrm{a}$ \\
\hline Rerata & $2,0 \mathrm{a}$ & $1,8 \mathrm{a}$ & $2,1 \mathrm{a}$ & $(-)$ \\
\hline Keterangan : & Angka pada baris dan kolom yang diikuti dengan huruf & yang sama \\
& tidak berbeda nyata menurut uji DMRT $\alpha$ & $5 \%$ & \\
& $(-)$ : Tidak terjadi interaksi antar faktor &
\end{tabular}

\subsection{Pembahasan}

Secara umum konsentrasi pupuk organik cair tidak memberikan pengaruh yang nyata terhadap pertumbuhan bibit sengon, tetapi berdasarkan hasil pengukuran beberapa parameter dapat diketahui bahwa konsentrasi $3 \mathrm{ml} / 1$ air merupakan konsentrasi yang optimum bagi pertumbuhan bibit sengon. Pemberian pupuk organik cair dengan konsentrasi $3 \mathrm{ml} / \mathrm{l}$ air memberikan pertumbuhan bibit sengon yang lebih baik berupa tanaman yang lebih tinggi dengan batang yang lebih besar dengan akar yang tidak terlalu panjang serta berat segar bibit yang paling ringan tetapi berat kering bibit sengon paling berat.

Pemberian pupuk organik cair dengan dosis $300 \mathrm{ml} /$ polybag memberikan pertumbuhan bibit sengon yang lebih baik berupa tanaman yang lebih tinggi dengan batang yang lebih besar, akar yang paling panjang, berat segar bibit yang paling ringan tetapi berat kering bibit paling berat. Dari parameter tinggi tanaman dan diameter batang dapat diketahui bahwa terdapat kecenderungan berupa tren semakin tinggi dosis maka bibit sengon akan berbatang semakin tinggi dan besar.

\section{Simpulan}

Tidak terjadi pengaruh interaksi antara konsentrasi dan dosis pupuk organik cair terhadap semua parameter. Konsentrasi pupuk organik cair hanya memberikan pengaruh nyata terhadap tinggi tanaman 30 HSS sedangkan dosis pupuk organik cair tidak memberikan pengaruh yang nyata terhadap semua parameter yang diamati. Konsentrasi pupuk organik cair $3 \mathrm{ml} / \mathrm{l}$ air merupakan konsentrasi yang optimum bagi pertumbuhan bibit sengon sedangkan dosis 300 $\mathrm{ml} /$ polybag adalah dosis yang tepat bagi bibit sengon.

Pustaka

BPS Kab. TTU, 2007. Timor Tengah Utara dalam Angka. Badan Pusat Statistik Kabupaten TTU, Kefamenanu.

Gomez, K.A., Gomez, A.A., 1984. Statistical Procedures for Agricultural Research. John Wiley \& Sons.

Gunawan, G., 2011. Untung Besar Dari Usaha Pembibitan Kayu. AgroMedia, Jakarta.

Hadiyan, Y., 2010. Evaluasi Pertumbuhan Awal Kebun Benih Semai Uji Keturunan Sengon (Sinonim:) Umur 4 Bulan Di Cikampek Jawa Barat. J. Penelit. Hutan Tanam. 7, 85-91.

Indah, T.K., 2006. Pengaruh Waktu Aplikasi Pupuk Kandang Ayam dan Konsentrasi Pupuk Organik Cair Terhadap Pertumbuhan dan Produksi Tanaman Cabai Rawit (Capsicum frutescens Linn.). Skripsi.

Lingga, P., 2003. Petunjuk Penggunaan Pupuk. Penebar Swadaya, Jakarta.

Lingga, P., Marsono, 2001. Petunjuk Penggunaan Pupuk. Penebar Swadaya.

Novizan, 2005. Petunjuk Pemupukan yang Efektif (ed. Revisi). AgroMedia, Jakarta.

Osman, F., 1996. Memupuk Padi dan Palawija. Penebar Swadaya, Jakarta.

Rambitan, V.M.M., Sari, M.P., 2015. Pengaruh Pupuk Kompos Cair Kulit Pisang Kepok (Musa paradisiaca L.) Terhadap Pertumbuhan Dan Hasil Tanaman Kacang Tanah (Arachis hypogaea L.) Sebagai Penunjang Praktikum Fisiologi Tumbuhan. J. EduBio Trop. 1.

Siregar, I.Z., Tedi, Y., Juwita, R., 2010. Кауи Sengon. Penebar Swadaya, Jakarta. 